\title{
MACHADO DE ASSIS, EXERCÍCIO LITERÁRIO
}

Ensaio originalmente publicado no Correio da Manhã, em 7 de outubro de $1940^{*}$

\author{
ÁLVARO LINS \\ APRESENTAÇÃO DE MARTA DE SENNA \\ Fundação Casa de Rui Barbosa/CNPq \\ Rio de Janeiro, Rio de Janeiro, Brasil
}

Resumo: O artigo trata da relativização como marca fundamental da ficção de Machado de Assis. Destacando a capacidade do escritor de afirmar negando, salienta que cada crítico de Machado, ao falar dele, fala na verdade de si mesmo, porque a obra machadiana se constitui como um espelho onde as fisionomias mais diferentes e contraditórias podem encontrar a sua forma e a sua expressão. Insistindo no caráter enigmático da ficção de Machado, o artigo ressalta ainda o mistério insondável de suas criaturas, a ausência de fronteiras nítidas entre a verdade e o erro, a contiguidade do amor e do ódio, a coexistência do bem e do mal.

Palavras-chave: crítica; subjetividade; relativização; ambiguidade; universalidade.

\section{MACHADO DE ASSIS, LITERARY EXERCISE}

Abstract: The article stresses relativization as a fundamental trait of Machado de Assis's fiction. By pointing out the writer's ability to make statements that contain their own denial, the article highlights that each Machadian critic talks about him/herself when talking about the author. This is due to the fact that his work functions as a mirror in which the most divergent and even opposing views can find their form and expression. As it insists on the enigmatic character of Machado's fiction, the article calls our attention to the unfathomable mystery of his creatures, the absence of a neat borderline between truth and error, the contiguity of love and hatred, the simultaneous existence of good and evil.

Keywords: criticism; subjectivity; relativization; ambiguity; universality.

\footnotetext{
* Os editores de Machado de Assis em linha: revista eletrônica de estudos machadianos agradecem aos eventuais detentores dos direitos do autor (a quem buscaram exaustivamente, mas em vão), na certeza de sua compreensão para o fato de que esta é uma publicação gratuita, disponível apenas na internet, dela não havendo nenhuma edição em suporte material, que pudesse vir a ser comercializada.
} 
O pernambucano Álvaro Lins (1912-1970) militou na crítica literária brasileira desde a década de 1930. Suas colunas nos diferentes periódicos em que atuou regularmente (Diário da Manhã, no Recife; Diário de Notícias e Correio da Manhã, no Rio de Janeiro) consagravam ou proscreviam novos escritores, refinavam a apreciação dos autores do cânone, contribuíam decisivamente para nele incluir novos nomes e, num exercício de metacrítica, comentavam o que se produzia na crítica literária de seu tempo.

Neste texto que escolhemos para integrar o número 18 de Machado de Assis em linha, o centro da atenção do autor é o então recém-publicado livro de Afrânio Coutinho, A filosofia de Machado de Assis (1940). ${ }^{1}$ Para chegar a isso (e a partir disso), Álvaro Lins tece interessantes considerações sobre a obra de Machado, dela fazendo uma avaliação geral que nos parece sustentar-se até hoje, 76 anos depois da publicação da matéria, no Correio da Manhã de 7 de outubro de $1940 .^{2}$ Aqui se publicam exatamente as passagens em que se encontram tais considerações.

Lins chama atenção para a relativização de absolutos como marca essencial da ficção de Machado, destaca a sua capacidade de afirmar negando e aponta para produções como "O alienista", Memórias póstumas de Brás Cubas e Dom Casmurro. Não que esmiúce qualquer dessas obras, não que as tome como exemplo da pavimentação do solo movediço que são os contos e romances do autor. Mas, por simplesmente mencioná-las, o crítico se revela arguto intérprete de Machado, cujos traços fundamentais desenha com nitidez nos relativamente poucos parágrafos dedicados exclusivamente a Machado. Indica ao leitor o que em Machado é eterno e universal: o mistério insondável de suas criaturas, a ausência de fronteiras nítidas entre a verdade e o erro, a contiguidade do amor e do ódio, a coexistência do bem e do mal.

As várias décadas de militância crítica de Álvaro Lins têm, nas passagens que selecionamos, vivo exemplo de seu vigor analítico, como constatará o leitor deste número de Machado de Assis em linha.

\footnotetext{
${ }^{1}$ Ver o número 7 (ano 4) de Machado de Assis em linha, em que publicamos um capítulo desse livro de Afrânio Coutinho, graças à generosa permissão do professor Eduardo Coutinho, filho do autor.

2 O texto foi localizado, no Arquivo Museu de Literatura Brasileira da Fundação Casa de Rui Barbosa, por Hélio de Seixas Guimarães, durante seu estágio de pós-doutorado nessa instituição, entre agosto de 2016 e abril de 2017.
} 


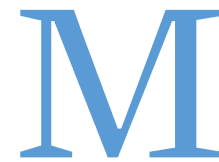
ais do que o autor principal da nossa literatura, mais do que um perfeito homem de letras, mais do que um permanente exemplo Machado de Assis representa, hoje, um assunto. Um exercício literário. Esta é uma circunstância que ajuda a explicar as numerosas tentativas de descrições biográfícas, de interpretações, de ensaios que se vêm levantando em torno da sua figura e da sua obra. Não é só Machado que os seus biógrafos e ensaístas acabam revelando; é a si mesmo que um autor exprime quando está exprimindo Machado. O criador de Brás Cubas permanece um espelho, onde as fisionomias mais diferentes e contraditórias podem encontrar a sua forma e a sua expressão. O que há na sua obra de oscilação, de vacuidade, de mistério excita a curiosidade e provoca a vontade tão humana de decifrar o enigma. A lição dos gregos, porém, se renova mais uma vez: aquele que pretende decifrar o enigma não decifrará senão a si mesmo. $\mathrm{O}$ enigma resulta sempre um mito. $\mathrm{A}$ sabedoria estará em buscar o segredo da esfinge como um meio e não como um fim.

Machado é o nosso enigma literário e também o nosso mito. Consequentemente, o mais ambicionado e o mais fascinante dos assuntos para os críticos e ensaístas. Todas as literaturas, aliás, possuem essas figuras-mitos (figuras centrais, fundamentais, essenciais) que servem não só de fontes de inspiração para outros autores, mas de exercício para os exegetas, sobretudo os jovens: na França, Montaigne; na Inglaterra, Shakespeare; na Alemanha, Goethe; na Espanha, Cervantes; na Itália, Dante. Mas enquanto outras literaturas apresentam mais de uma dessas figuras que se poderiam chamar simbólicas, o Brasil - dentro deste critério particular a que estou aludindo apresenta somente uma. Escrever sobre Machado de Assis importa, pois, na utilização de um tema riquíssimo e inesgotável. Importa também na certeza de que podemos ficar situados para além do bem e do mal, para além do erro e da verdade, para além de todos os critérios e de todas as limitações. Pois, se a obra de Machado significa uma afirmação suprema de relatividade e oscilação entre erro e verdade (ver, de maneira particular, o conto "O alienista"), um permanente desencontro sobre a origem e o destino dos homens, uma trágica visão da inanidade das coisas pela ausência de um seguro ponto de apoio - como exigir que se ofereça a seu respeito uma interpretação única, certa, exata? 
Dentro daqueles romances, daqueles contos, daquelas crônicas - o que é regular, certo, exato? Cada um fica, portanto, com a liberdade de ter sobre Machado a sua verdade e a sua visão. Podemos discordar delas porque não se ajustam com as nossas, mas nunca porque possamos dizer que sejam erradas. Uma dúvida sempre se levantará: a visão verdadeira será a nossa ou será a visão contrária? Machado não respondeu na sua primeira vida; não responderá mais nesta segunda. A única resposta possível e implícita está no gesto de Simão Bacamarte, no encerramento na Casa Verde, na loucura que resulta do esgotamento em busca da verdade...

Não é só a obra de Machado que, na sua aparente transparência, se apresenta misteriosa, mas também a sua figura, a sua vida, os seus problemas. Não que ele não afirme e negue: não fez outra coisa senão afirmar, negando, e negar, afirmando. Mas tudo num plano de relatividade e de ceticismo: sempre pela metade, sempre reticente, sempre duvidando, em essência, tanto das suas afirmações como das suas negações. Esta possibilidade de se deixar completar e prolongar representa, ela mesma, a grandeza da arte machadiana; e também o segredo da sua perpetuidade: haverá, em todas as gerações, a ambição insatisfeita de prolongá-lo e completá-lo. Ainda neste ponto, apresenta-se excepcional em nossa literatura. O que é comum, entre nós, é o autor confessando-se todo na sua obra, nas suas entrevistas, nas suas conversas; é o autor matando, com um golpe só, toda a curiosidade e todo o interesse que provoca. Machado, não. Quando muito, sugere, deixa o pensamento no ar, entreabre a porta.

Excepcional ainda se apresenta Machado no exemplo em que se constituiu, pessoalmente, como um homem de letras. Acredito que esse exemplo, dadas as condições da nossa vida literária, é tão importante, para nós, quanto a sua obra. Quero me referir à posição que ele escolheu e à qual ficou fiel a vida toda. A posição de um homem que nada foi, que nada quis ser além de um homem de letras. Esta posição - tão característica e tão própria do ofício literário - constitui, no Brasil, uma raridade. A literatura tem sido, quase sempre, para os nossos autores, um instrumento ou um derivativo. Um instrumento para empregos, para ascensões políticas, para situações sociais. Ou, então, um derivativo, como meio de encher os ócios do ostracismo, como distração, como complemento de boemia. Eis por que a nossa vida literária tem o aspecto de um tumultuoso "exército do Pará". Raros os casos como o de 
Nabuco, que, pelas suas condições especiais, atingiu o equilíbrio e a harmonia entre a ação política e a ação literária. Machado de Assis, porém, coloca-se acima de qualquer divisão e se constitui um tipo exclusivo de escritor. É verdade que, não podendo ser um profissional das letras, aceite um ofício de repartição pública. Estasional das letras, aceita um ofício da repartição e o ofício das letras, uma linha divisória: ${ }^{3}$ dois mundos, dois homens, duas atitudes. Lembro-me, a propósito, que o sr. Olívio Montenegro, no seu livro O romance brasileiro, compara Machado de Assis com o dr. Jeckyll, personagem de uma novela de Stevenson. É uma comparação que revela o autor de Dom Casmurro na sua imagem mais feliz: "o dr. Jeckyll era um médico que todo mundo admirava e estimava pelo seu espírito sério, a sua doçura, a sua modéstia, até que ele usava uma droga de sua descoberta, e virava outro caráter - um caráter de demônio". Como o dr. Jeckyll, Machado apresentava duas faces: uma artificial e convencional, a da vida comum; a outra, a verdadeira, esta só se revelava no seu gabinete e diante das folhas em branco: a da vida literária. E esta personalidade, ele a resguardou contra todas as seduções e todas as solicitações estranhas à literatura. Por isto, o seu legado não é só o da sua obra; é, igualmente, o da sua figura de autor.

\section{$[\ldots]$}

Quanto a mim, hesito em colocar Machado nesta família de autores que se caracteriza pelo ódio à vida e de que Pascal é um representante típico. ${ }^{4}$ Como seria Carlyle. Ou Swift. Pois o processo de exprimir este ódio (o panfleto: Carlyle; o humour: Swift) importa pouco. O fenômeno de Machado, porém, difere de todos estes, o que não quer dizer que seja um membro da família oposta: a dos adoradores da vida. Menos do que o ódio à vida o seu caso é o do conhecimento lúcido e profundo (não sentimental, portanto) dos homens e da vida. Poder-se-á dizer que este conhecimento é pessimista e injusto. Uma nova

\footnotetext{
3 Assim está no original do Correio da Manhã, em provável sucessão de erros tipográficos e empastelamento de linhas.

${ }^{4} \mathrm{Na}$ passagem suprimida, o autor se detém na análise do livro A filosofia de Machado de Assis, em que Afrânio Coutinho explora, de maneira particular, as relações entre o pensamento de Pascal e a obra machadiana. Retomamos o texto neste parágrafo, porque nele Álvaro Lins novamente abre o foco de sua lente crítica para a obra de Machado, como fizera nos parágrafos iniciais.
} 
dúvida, porém, se levantará sempre: será Machado o pessimista ou somos nós os otimistas? Fico tentado, como se conclui, a julgá-lo um realista. Um realista como o autor do Eclesiastes. Que tenha observado e revelado os homens e os atos humanos nos seus aspectos mais cruéis e mais desgraçados - esta circunstância não significa rancor, mas imparcialidade. Nem mesmo demonstra, em tese, um deliberado desinteresse pelo destino dos homens. É que o pretendido interesse desta espécie não é um objetivo de sentimentos artísticos e sim de sentimentos pessoais. E nunca um artista como Machado permitiria, na sua obra, uma confusão tão lamentável. O papel do artista nada tem a ver com o sentimento pessoal que oscila segundo as paixões do momento: o seu destino é observar a realidade física e psíquica e recriá-la em formas sensíveis de objetividade estética. Não confundamos, portanto, o sentimento artístico de uma obra literária com o sentimento pessoal de um homem em sociedade humana. Espero, mais tarde, poder desenvolver esta opinião para mostrar que o famoso ódio à vida, em Machado, nada significa além de uma aparência. Tentarei a revisão tomando como ponto de partida esta frase extremamente reveladora de Machado - "nem ele a odiou tanto senão porque a amava muito". 5 Nem amor nem ódio, na verdade: uma maneira negativa (como está muito de acordo com os seus processos) de afirmar um sentimento diferente.

\section{Errata}

No artigo "Machado de Assis, exercício literário", com número de DOI: 10.1590/1983-682120169181, publicado no periódico Machado de Assis em linha, 9(18): 03-08, na página 03 onde se lia:

"Ensaio originalmente publicado no Correio da Manhã, em 7 de outubro de 1940" leia-se:

"Ensaio originalmente publicado no Correio da Manhã, em 7 de dezembro de $1940 "$

5 Trata-se da última frase do conto "Viver!", publicado por Machado de Assis em Várias histórias (1896). 